\title{
Access to Weather Forecasting and Early Warning Information by Communal Farmers in Seke and Murewa Districts, Zimbabwe
}

\author{
Shakespear Mudombi ${ }^{1}$ and Godwell Nhamo ${ }^{2}$
}

\begin{abstract}
In the context of current climate variability and the projected climate change there is need to strengthen the resilience of communities particularly those whose livelihoods are highly sensitive to change. Climate change is likely to result in increased frequency and intensity of weather and climate extremes. The first objective of the present research was to analyze how communal farmers in Seke and Murewa districts of Zimbabwe accessed weather forecasting and early warning information. The second objective was to assess how access to such information influenced their farming decisions. The data was collected in 2011, using a general survey of 300 communal farmers and interviewing key informants. The findings show that the two districts are and will be more vulnerable to dry spells, droughts and to some extent, violent storms. There was a general lack of access to timely, reliable rainfall forecasts and early warning information on droughts and violent storms. For those that had access to the information, the main channels that transmitted the information were the radio, extension, the television, and the farmers enquiring directly. The radio was the most important channel. Besides, the information being perceived as not very reliable, it played a significant role in the decision-making process of farmers, particularly, when deciding the time to plant and choosing crop varieties. A serious constraint for the farmers was lack of complementary information, inputs and technology that could be used to adjust their farming operations, in line with the forecasts.
\end{abstract}

KEYWORDS Droughts. Storms. Rural Farmers. Adaptation. Preparedness. Climate Change

\section{INTRODUCTION}

Climate change leads to changes in the frequency, intensity, spatial extent, duration, and timing of extreme weather and climate events (IPCC 2012). In southern Africa, rainfall is likely to de- crease in much of the winter rainfall region and western margins, whereas in East Africa, there is likely to be an increase (UNEP 2003; Christensen et al. 2007). Consequently, food shortages, water shortages, floods and storms are likely to increase throughout most of Africa (UNEP 2003). Even though sub-Saharan Africa (SSA) is not the most disaster prone region, regrettably it is the most vulnerable to meteorological, hydrological and climate related disasters and impacts (World Bank and UN/ISDR 2007).

Worse still, the changing geographic distribution, frequency and intensity of weather-related hazards are threatening and undermining the resilience of communities (UN/GARDRR 2009). Fischer et al. (2002) called for the need to strengthen the resilience of the poor and the vulnerable against climate variability and change. Availability of climate information is a prerequisite for climate-informed decision making (Dinku et al. 2014). In this context, studying the use of forecasts helps to anticipate use patterns, improve information and decision support tools, increase the effectiveness of forecast dissemination and contribute to improved preparedness (Pfaff et al. 1999; Letson et al. 2001; Mase and Prokopy 2014). In addition, such analysis is needed to understand how forecast information is transformed into knowledge that is useable in decisionmaking (Coughlan and Mason 2014). Thus, key farming decisions that are sensitive to weather and climate information have to be identified (Stone and Meinke 2006).

\section{OBJECTIVES}

- The first objective of the paper was to ana- lyze how communal farmers in Seke and Murewa districts of Zimbabwe accessed weather forecasting and early warning information.

- The second objective was to assess how access to such information influenced their farming decisions. 


\section{THE WULNERABILITY OF THE AGRICULTURAL SECTOR TO CLIMATE CHANGE}

Rain-fed agriculture is the dominant source of food production and the livelihood foundation of the majority of rural people in sub-Sahar- an Africa (Cooper et al. 2008; Hope 2009). This is the case in Zimbabwe. The agricultural sector plays an important role in the national economy, food security and household income (Mutekwa 2009). To be specific, the agricultural sector con- tributes about 15\% each year to the country's GDP (Ministry of Environment and Natural Re- sources Management 2013). Worryingly, agriculture is one of the sectors hardest hit by climate variability and change (Vogel 2005; Nhamo 2009), particularly subsistence farming (Winsemius et al. 2014). Due to the fact that the country's agriculture is mainly rain-fed, any rainfall changes will have a direct impact on agricultural performance (Chagutah 2010). The most unfavorable climate change projections are mainly for the tropics and sub-tropics where most developing countries that are highly dependent on climate sensitive sectors are located (Leary et al. 2007). This scenario paints a gloomy picture on the agricultural sectors and economies of countries like Zimbabwe. If agriculture is negatively affected, this will have negative repercussions on the economy. Thus,climate change becomes an additional constraint to sustainable socioeconomic development of the country (Unganai 2009). In order to reduce the risk and likely negative impacts of climate extremes on agricultural communities, anticipatory adaptation is of importance. One way of promoting anticipatory adaptation is through the provision and utilization of weather forecasting and early warning information.

\section{IMPORTANCE OF WEATHER FORECASTING AND EARLY WARNING INFORMATION IN AGRICULTURAL COMMUNITIES}

Responding to climate variability and change in agricultural communities will be incomplete without access to weather forecasting and early warning information. The forecasts can provide advance information so that farmers can adjust critical agricultural decisions, thereby improving efficiency, and enabling them to adopt the most suitable coping strategies (Hansen et al. 2006; World Bank 2012). Recent advancement in the form of seasonal forecasting provides a basis for early warning (Murphy et al. 2001). An Early Warning System (EWS) involves the pro- vision of timely and effective information, through identified institutions, which enables individuals exposed to a hazard to take action to avoid or reduce their risk and prepare for effective response (UN/ISDR 2010). The importance of early warning systems in enhancing timely and effective responses to cli- mate impacts is emphasized in the literature (for example, Alliance of the CGIAR Centers 2009; Houghton 2009; Karanasios 2011; World Bank 2012). Preparedness to events such as violent storms, floods, and droughts is very important in reducing vulnerability. In order for communal areas such as Seke and Murewa to be prepared, there should be early warning systems in place to disseminate information so that people to take necessary action in advance. Nonetheless, many of the promising opportunities provided by ear- ly warning and climate information have not been fully exploited (Vermeulen et al. 2010). Dinku et al. (2014) noted that the availability and access to such information and the ability to use it, is a serious challenge in most rural areas across the continent. In Zimbabwe, the climate forecasts are pro- vided by the Meteorological Service Department (Met Office), which then disseminates the information to users through various routes (EMA 2010). The routes include the print and electron- ic media, agricultural extension system, and various meteorological stations across the country. In addition, the country has a National Early Warning Unit (NEWU) whose mandate is to con- duct risk analysis, interpretation, dissemination of disaster warnings, and providing advance food security information (Chagutah 2010; EMA 2010). The NEWU is complemented by the SADC Regional Early Warning Unit, Famine Early Warning System (FEWSNET), the Zimbabwe Vulnerability Assessment Committee (ZIMVAC), the Department of Agricultural Technical and Extension Services (AGRITEX) (Chagutah 2010).

\section{METHODS}

The data was collected in 2011, using a general survey of communal farmers and interviewing key informants. The ethical clearance was sought from the university. In addition, the clearance to undertake data collection in the study area was sought from the Government of Zimbabwe through the Ministry of Local Government, Rural and Urban Development, and the respective offices of the District Administrators in the two districts. Steps were taken to avoid risk and harm to participants, non-participants, and organisations involved. Due to a number of reasons including the unavailability of sampling frames at the district level, a multi-stage sampling approach that involved a combination of purposive and cluster sampling was used. Purposive sampling was used to select the province and the subsequent selection of the two districts. One of the desired characteristics was to have two rural districts, one of which was supposed to be closer to a major urban area while the other district was relatively far. The districts' proximity to urban areas was important, as there was a need to evaluate its influence in relation to the objectives of the paper. Based on this criterion, Mashonaland East province was selected from the country's 10 provinces. The province has 11 districts, from which 2 districts namely Seke and Murewa were selected. Seke (rural) district is adjacent to the major urban centres namely, Chitungwiza town and Harare the capital city, while Murewa district is relatively far from these urban centres (about 100 kilometres). Having selected the province and the two districts, three wards were purposively selected in each district based on the criterion of geographical spread across each district. Cluster sampling was then used to select five villages 
(clusters) in each of the three wards. At the village level, the sampling units were selected systematically according to the sampling frames that had complete list of all households in the village. A total of 300 respondents (150 from each of the two districts) were interviewed. In terms of key informant interviews, a snowballing sampling approach was used. Based on the 2002 census, Zimbabwe had a total population of about 11634663 people, with Mashonaland East province having a total population of about 1127413 people and 309198 households (CSO 2004). About 90 percent of the population resided in rural areas. Agriculture is the main livelihood activity in the two districts. The country's climate is mainly semi- arid, characterised by limited and unreliable rainfall patterns (Chagutah 2010). The two districts have climates associated with natural agro-eco- logical region II; with an average rainfall of $500-700 \mathrm{~mm}$. The data collected covered various aspects of access to weather forecasting and early warning information. The Statistical Package for Social Scientists (SPSS) package was used for data entry and descriptive statistics (frequencies and percentages).

\section{RESULTS}

Due to the importance and direct bearing of rainfall on the livelihoods of rural people, this paper concentrated on the respondents' perceptions on rainfall and rainfall-related climate extremes. Rainfall is an important climate variable whose amount and variation has a bearing on the frequency and intensity of events such as droughts, floods and violent storms. The results are organised as follows. First, it presents results on perceptions on rainfall, droughts, violent storms and floods. Next it presents results on access to and use of forecasting and early warning information. Finally, it presents results on the role of forecasting information in farm decision-making.

\section{PERCEPTIONS ON RAINFALL, DROUGHTS, VIOLENT STORMS, AND FLOODING}

The respondents were first asked whether they received adequate rainfall. About 60 per- cent of respondents in Murewa indicated that they received adequate rainfall, while in Seke it was about 17 percent. The perceptions of respondents were confirmed by responses of the key informants. In Murewa the key informants indicated that the area received adequate rain- fall while those in Seke indicated that the area received inadequate rainfall. In terms of dry spells, the key informants in Murewa indicated that the area experienced at least one dry spell in a season. In Seke, the key informants indicated that the area experienced one to two dry spells. Such dry spells lasted for about one to four weeks and at times could extent to more than four weeks. The dry spells could result in the wilting of some crops with significant effects on yields, as well as affecting both pastures and water avail- ability for livestock. The respondents were asked if they had ever experienced a drought. Almost all respondents in both districts (98 percent in Murewa and 95 percent in Seke) indicated that they had experienced a drought. For those who indicated that they had experienced a drought they were further asked how many droughts had they experienced in the last ten years. A greater percentage of respondents in Murewa, about 43 percent indicated that they had experienced two droughts, followed by 27 percent who indicated that they had experienced one drought in the last ten years. This was also supported by the key informants who indicated that on average Murewa had experienced about two droughts in the last ten years. In Seke, a greater percentage of re- spondents, about 47 percent indicated that they had experienced three droughts, followed by 21 percent who indicated that they had experienced two droughts in the last ten years. The key in-formants in Seke were in agreement with the overall perception of the majority that the area had experienced about three droughts in the last ten years. Moreover, a greater proportion of respondents in both districts perceived that the frequency of droughts was increasing. In terms of violent storms, just over half of the respondents in both districts (52 percent in Murewa and 54 percent in Seke) indicated that they had experienced a violent storm. A greater percentage of those respondents in Seke indicated that they had experienced one violent storm in the last ten years, followed by those who indicated that they experienced two violent storms. Largely, the key informants in Seke indicated that the area had experienced about two violent storms in the last ten years. In Murewa, a greater percentage of those respondents indicated that they had experienced two violent storms in the last 10 years, followed by those who indicated that they had experienced one violent storm. The key informants in Murewa indicated that the area had experienced about one to two violent storms in the last ten years. The respondents were then asked if they had observed any change in frequency of violent storms. The greatest percentage of respondents in both districts perceived that the frequency of violent storms was decreasing, with about 46 percent and 54 percent in Murewa and Seke respectively. In terms of floods, none of the respondents and key informants in both districts indicated that they had experienced flooding in the area. 


\section{ACCESS TO AND USE OF FORECASTING AND EARLYWARNING INFORMATION}

Almost all respondents in both districts (about 98 percent in both districts) indicated that it was important to know about the likely amount and distribution of rainfall in the coming sea- son. Respondents were then asked if they got to know or accessed information on the likely amount and pattern of rainfall in the coming sea- son. About 65 percent of respondents in Murewa and about 52 percent in Seke indicated that they got to know about rainfall in the coming season. In terms of droughts, about 59 percent in Murewa and about 36 percent in Seke indicated that they got timely warnings. In terms of violent storms, about 36 percent in Murewa and 30 percent in Seke indicated that they got timely warnings. Though the two districts are not prone to floods, the respondents indicated that they also got warning on floods probably concerning other areas that are flood prone.

\section{MAIN SOURCES OF INFORMATION}

Sources of weather forecasting and early warning information include modern methods, traditional experts, and farmer's own assessment/ observation. This paper focused mainly on access to forecasting information from modern methods. More than half of the respondents in the two districts indicated that they accessed weather forecasting information from weather stations, with about 72 percent in Murewa and 54 percent in Seke. The respondents in both districts ranked the radio as the most important channel for accessing information (Table 1). In Murewa, the radio was followed by extension and the television (TV). In Seke, the radio was followed by extension and direct enquiry which were ranked equally. Respondents were asked how they perceived the reliability of the modern forecasting information (that is information from Meteorological Service Department). None of the respondents in Seke and only one percent in Murewa indicated that the weather forecasting information was 'very reliable'. The majority of respondents (about 78 percent in Seke and 70 percent in Murewa) perceived that the forecasting in- formation was only 'reliable at times'. Besides the majority of respondents indicating that the information was only 'reliable at times', over 90 percent of them in both districts indicated that it was important to have access to such information

Table 1: Results on information sources; factors influencing farming decisions; and main uses of information

\begin{tabular}{|c|c|c|c|c|}
\hline \multirow[t]{2}{*}{ Category } & \multirow[t]{2}{*}{ Variable } & \multicolumn{3}{|c|}{ District } \\
\hline & & & Murewa (\%) & Seke (\%) \\
\hline \multirow{8}{*}{$\begin{array}{l}\text { Important Sources of } \\
\text { Weather Information }\end{array}$} & Radio & 63 & 53 & \\
\hline & Extension & 23 & 6 & \\
\hline & Direct enquiry & 3 & 6 & \\
\hline & TV & 5 & 3 & \\
\hline & Other farmers & 1 & 3 & \\
\hline & Newspaper & 0 & 1 & \\
\hline & Mobile phone & 1 & $i$ & \\
\hline & Farming magazines & 0 & 1 & \\
\hline \multirow{6}{*}{$\begin{array}{l}\text { Ranking of Factors that Influenced } \\
\text { Farming Decisions }\end{array}$} & Inputs costs & 45 & 36 & \\
\hline & Weather and climate information & 32 & 38 & \\
\hline & Output price expectations & 19 & 24 & \\
\hline & Crop rotations & 3 & 1 & \\
\hline & Other & 2 & 1 & \\
\hline & Soil tests & 0 & 1 & \\
\hline \multirow{7}{*}{$\begin{array}{l}\text { Main Uses of the Weather and } \\
\text { Climate Information }\end{array}$} & Choice of planting dates & 37 & 37 & \\
\hline & Choice of crop varieties & 37 & 37 & \\
\hline & Choice of land preparation methods & 16 & 14 & \\
\hline & Fertilizer and other inputs to use & 10 & 14 & \\
\hline & More knowledge & 11 & 2 & \\
\hline & Choice of harvesting dates & 4 & 0 & \\
\hline & Marketing decisions & 3 & 0 & \\
\hline
\end{tabular}

Source: Survey data 


\section{THE IMPORTANT ROLE OF FORECASTING INFORMATION IN FARM DECISION-MAKING}

There are many decisions that a farmer has to make in his/her farming activities. In relation to this, the respondents were asked about the factors that influenced their farming decisions most (refer to Table 1). The three highly ranked factors that influenced farming decisions in Murewa were inputs costs, weather and climate information, and output price expectations. In Seke, the three highly ranked factors were weather and climate information, input costs, and out- put price expectations. These results indicate that weather and climate information is very important in influencing farming decisions. Actually, very few respondents (only three percent in Murewa and five percent in Seke) indicated that their decisions were 'not at all' influenced by such information. Further, the respondents were asked to rank farming decisions that were mostly influenced by the forecasting information (Table 1). In both districts, the most important decisions were deciding planting dates and choosing crop varieties. In Murewa, this was followed by choice of land preparation method, then more knowledge, and deciding on the application of fertilizer and other inputs. In Seke, they were followed by deciding on application of fertilizer and other inputs, then choice of land preparation methods, and more knowledge.

In addition, to the actual forecasting information, farmers should have information and knowledge on how to adjust their farming practices according to the forecasts. Regrettably, about 41 percent of respondents in Murewa and 56 percent of respondents in Seke indicated that they did not have knowledge on how to adjust their farming practices according to the fore- casts they received. In addition, about 47 percent of respondents in Murewa and 60 percent in Seke indicated that they did not have information or knowledge on the seed varieties and technologies that were suitable (that is, in line with the forecasts). In other words, they did not have information, for example on drought-resistant seeds, if a drought was predicted or were not aware where such seeds or technologies could be sourced from. Worse still, for those that indicated that they had such information and knew where the suitable seeds or technologies could be sourced, only 54 percent of them in Murewa and 37 percent of them in Seke indicated that they could afford them.

The key informants indicated that though suitable seed varieties and technologies were generally available on the market, the majority of the farmers could not access them. This is mainly due to the inputs not being available on time, as well as, their unaffordability. Further, the key informants highlighted that farmers faced additional challenges. These include lack of proper access to print and electronic media, wrong prediction of weather forecasts, and difficulties in interpreting weather forecasts. Extension workers (an important and trusted source of fore- casting information) also faced challenges in conveying forecast information to the farmers. One extension worker remarked that in some instances they did not know what to tell the farmers concerning rainfall forecasts, mainly due to lack of timely weather information and at times having information that is too general, which was not relevant at the local level.

\section{DISCUSSION}

Drawing from the respondents' perceptions, it is clear that the two districts are and will be more vulnerable to dry spells, droughts and to some extent, violent storms. These events can result in devastating effects on the livelihoods of rural people. This necessitates the need for them to be better prepared for such events. Unfortunately, the findings in the present research show that a significant proportion of respondents did not access timely forecasting and early warning information. Other studies have made similar observations. For example, a study con- ducted by Gwimbi (2009) in Gokwe District of Zimbabwe, reveal that more than 70 percent of the surveyed farmers lacked access to timely weather forecasts. Further, related studies (for example, Pfaff et al. 1999; Goddard et al. 2001; Ziervogel et al. 2004; Lemos and Dilling 2007) highlight that forecasts have not been extensively embraced and their effective utilisation has lagged behind, particularly among marginal groups. While the majority of farmers did not have access to timely weather forecasting and early warning information, this information is very important. The farmers need timely advance information in terms of the number of days it will rain, the rainfall amount during the cropping sea- son, and the likely quality of the upcoming sea- son (Dilley 2000; EMA 2010). The weather forecasting and early warning information should not only be available, but more importantly it should be understandable, reliable, credible, trusted, relevant, useful, appropriate and context specific to the users for it to have a positive impact (EMA 2010; World Bank 2012; Mase and Prokopy 2014; Winsemius et al. 2014). In the present research, fewer respondents indicated that the information they received was reliable, rather the majority of respondents indicated that the information was only 'reliable at times'. It is vital to point out that the reliability of forecasts is dependent on both the skill of the forecast and the credibility of the source (Ziervogel et al. 2004). 
In addition, the skill of the forecast is also affected in part by the reliability of the equipment that is used in the forecasting process. Unfortunately, most cli- mate observation networks in Africa are con- strained by lack of stations, equipment and maintenance (The UNFCCC 2007). In Zimbabwe, the meteorological equipment is outated (EMA 2010; The Herald 2012). This negatively affects the generation of forecast information and its subsequent transmission. Farmers have to follow and respond to the forecasting information. Nevertheless, in some cases, poor forecasts may actually do more harm than good (Ziervogel et al. 2004). For example, in Zimbabwe, a late 1997 forecast suggesting a more severe drought than the one experienced contributed to a reduction in planting and out- put (Pfaff et al. 1999). Mwando (2012) reports that, "the Met office has been off the mark many times in the past with its weather predictions, which are now questioned by farmers and disaster preparedness organisations". This can be attributed to the credibility constraint that arises from having inaccurate past forecasts. It occurs when forecasts are communicated in a deterministic, rather than probabilistic form (Patt and Gwata 2002). In this context, Mase and Prokopy (2014) note that while increasing fore cast skill and reliability would help, it is also critical to convince farmers of the improved ac- curacy and trustworthiness of this information.

The majority of respondents indicated that the forecasting information strongly influenced their farming decisions. This implies that improvements in the reliability of this information can have positive impacts on farming activities. In the present research, respondents ranked deciding the planting dates and the choice of crop varieties as the most important farm decision-making activities that were influenced by the forecasting information. These findings corroborates with the study of Letson et al. (2001) that was conducted in Pergamino, Argentina in which respondents indicated that they would most likely change the crop mix, planting date, cultivar, and fertilizer amounts based on climate forecasts. Forecasting information is only important if farmers can access and utilise the information, and if it meets their needs and context (Thorn- ton et al. 2011; World Bank 2012). This implies that having access to forecasting information is not enough on its own. For example, if the early warning system accurately predicts a drought but does not give the vulnerable people the necessary information on how to cope, then the usefulness of such information is limited (Mu- dombi and Muchie 2010). Thus, in addition to the information on the expected state of weather and climate variables, farmers require information and knowledge on appropriate response strategies. Regrettably, in the present paper about half of the respondents did not have the knowledge and capacity to adjust their farming practices according to the forecasts they received. The general lack of alternatives, both in terms of inputs, technology and access to financial and human resources, acts as a serious hindrance to the use of forecasts (Lemos and Dilling 2007; World Bank 2012). The farmers, who have the means and resources to take advantages, and apply productivity enhancing technologies, will get the greatest benefits (Stone and Meinke 2006). Thus, improving the generation and presentation of forecasting information and addressing the barriers to its usage should be coupled by investing in the decision-making context (Coughlan and Mason 2014).

In the present research, farmers accessed forecast and early warning information through the radio, extension, direct enquiry, TV, other farmers, newspapers, mobile phone, and farming magazines. Other studies have also found these channels to be important in conveying forecast information. For instance, a study con-ducted in Bangladesh, Ghana and Uganda by Chaudhury et al. (2012) found that radios, news- papers, mobile phones, public announcements at schools and during religious gatherings, and print media were important channels for receiving weather forecast information. The findings in the study and also in the literature show that information and communication technologies (ICT) and personal channels play an important role in the dissemination of forecast information. Personal channels such as extension workers compliment ICTs by providing the important links between the early warning system and the effective use of that information by local com- munities (Gurstein 2005). Extension workers in Seke and Murewa districts played an important in conveying forecasts to farmers. However, like the findings of Murphy et al. (2001); the present study found that the extension workers faced challenges. These include not knowing or not sure of what to tell the farmers, the lack of local- specific forecast information, having wrong or untimely forecasts, and their misinterpretation. These findings call on the need to intensify the extension workers' training on interpreting and conversion of weather data into extension messages (The Herald 2012). This is very crucial because trusted sources of advice and information are valuable in increasing the use of weather and climate information in agriculture (Mase and Prokopy 2014). Additionally, there is need to enhance the reliability of the information, as well as training farmers on the interpretation and use of the forecasts. There are a number of ways for improving smallholder farmers' access to climate information and services. For instance, Tall et al. (2014) identified the need to involve farmers in the co- design, co-production and co-evaluation of cli- mate services; establishing partnerships that bridge the gap between climate, agricultural re- search and farmers; utilising scalable communication channels to reach "the last mile"; continuously assessing the need to improve service delivery; and proactively engaging and targeting the needs of the vulnerable and marginalised groups. In addition, efforts to improve the provision of the information should be complemented by integrating climate issues into development practices (Dinku et al. 2014). 


\section{CONCLUSION}

The findings show that Seke and Murewa districts are and will be more vulnerable to droughts and to some extent to violent storms. This necessitates the need for individuals and the community at large to be better prepared for such events especially now with the projected climate change. The present research found that there was a general lack of access to timely rain- fall forecast and early warning information on droughts and violent storms. Some of the main channels that transmitted the information were the radio, extension, the television, and the farmers enquiring directly. The radio was the most important channel. Besides, the forecast and early warning information, being perceived as not very reliable, it played an important role in the decisionmaking process of farmers, particularly, when deciding the time to plant and choosing crop varieties. A serious constraint for farmers was lack of complementary information, in- puts, and technology that could be used to ad- just their farming operations, in line with fore- casts. The forecast and early warning information is important as it notifies individuals and communities of the need to take action; nevertheless, without the means to act, the useful- ness of such information is limited.

\section{RECOMMENDATIONS}

There is need to enhance farmers' timely access to reliable forecasting and early warning information. The government and other bodies should help in improving reliability of forecasts and early warning information through upgrading and maintaining meteorological stations and equipment, and enhancing the skills of the personnel. In addition, there is need to promote various channels in the transmission of the in- formation. In addition, extension workers and farmers should be trained on the interpretation and use of forecasts. Overall, there is need to enhance the knowledge and capacity of farmers in terms of general preparedness and adaptation to climate variability and change through provision of complementary information, inputs and technology.

\section{ACKNOWLEDGEMENTS}

The data were collected during implementation of the ATPS Phase VI Strategic Plan, 2008-2012, funded by ATPS donors, including the Ministerie van Buitenlandse Zaken (DGIS), The Netherlands. The authors wish to thank the ATPS for the financial and technical support during the implementation of the program.

\section{REFERENCES}

Alliance of the CGIAR Centers 2009. Climate, Agriculture and Food Security: A Strategy for Change. From <http://www.cgiar.org/www.archive/www. cgiar.org/pdf/CCAFs_Strategy_december 2009.pdf> (Retrieved on 20 August 2014).

Chagutah T 2010. Climate Change Vulnerability and Adaptation Preparedness in Southern Africa: Zimbabwe Country Report. Cape Town: Heinrich Böll Stiftung Southern Africa.

Chaudhury M, Kristjanson P, Kyagazze F, Naab JB, Neelormi S 2012. Participatory Gender-sensitive Approaches for Addressing Key Climate Change- related Research Issues: Evidence from Bangladesh, Ghana, and Uganda. Working Paper 19. Copenhagen: CGIAR Research Program on Climate Change, Agriculture and Food Security (CCAFS).

Christensen J, Hewitson B, Busuioc A, Chen A, Gao X et al. 2007. Regional climate projections. In: S Solomon, D Qin, M Manning, Z Chen, M Marquis, K Averyt et al. (Eds.): Climate Change 2007: The Physical Science Basis. Contribution of Working Group I to the Fourth Assessment Report of the Intergovernmental Panel on Climate Change. Cambridge: Cambridge University Press.

Cooper PJ, Dimes J, Rao KP, Shapiro B, Shiferaw B et al. 2008. Coping better with current climatic variability in the rain-fed farming systems of sub-Saharan Africa: An essential first step in adapting to future climate change? Agriculture, Ecosystems and Environment, 126: 24-35.

Coughlan de Perez E, Mason SJ 2014. Climate information for humanitarian agencies: Some basic principles. Earth Perspectives, 1(11): 1-6.

CSO 2004. Census 2002: Provincial Profile - Mashonaland East. Harare: Central Statistical Office. 
Dilley M 2000. Reducing vulnerability to climate variability in southern Africa: The growing role of climate information. Climate Change, 45: 63-73.

Dinku T, Block P, Sharoff J, Hailemariam K, Osgood D, del Corral J, Cousin R, Thomson MC 2014. Bridging critical gaps in climate services and applications in Africa. Earth Perspectives, 1(15): 1-13.

EMA 2010. Coping with Drought and Climate Change Project: Capacity Needs Assessment and Strategy for Enhanced Use of Seasonal Climate Forecasts for Small-holder Farmers in Chiredzi District. GoZUNDP/GEF Final Report. Harare: Environmental Management Agency.

Fischer G, Shah M, van Velthuizen H 2002. Climate Change and Agricultural Vulnerability. Vienna: International Institute for Applied Systems Analysis (IIASA).

Goddard L, Mason SJ, Zebiak SE, Ropelewski CF, Basher R et al. 2001. Current approaches to seasonal-tointer annual climate predictions. International Journal of Climatology, 21: 1111-1152.

Gurstein M 2005. Tsunami warning systems and the last mile: Towards community based and ICT enabled disaster response systems. The Journal of Community Informatics, 1(2): 14-17.

Gwimbi P 2009. Cotton farmers' vulnerability to cli- mate change in Gokwe District (Zimbabwe): Impact and influencing factors. JAMBÁ: Journal of Disaster Risk Studies, 2(2): 81-92.

Hansen JW, Challinor A, Ines A, Wheeler T, Moron V 2006. Translating climate forecasts into agricultural terms: Advances and challenges. Climate Re-search, 33: 27-41.

Hope KR 2009. Climate change and poverty in Africa. International Journal of Sustainable Development and World Ecology, 16(6): 451-461.

Houghton J 2009. ICT and the environment in developing countries: An overview of opportunities and developments. Communications and Strategies, 70(4th quarter): 39-60.

IPCC 2012. Summary for policymakers. In: CB Field, V Barros, TF Stocker, D Qin, DJ Dokken, KL Ebi, MD Mastrandrea, KJ Mach, G-K. Plattner, SK Allen, M Tignor, PM Midgley (Eds.): Managing the Risks of Extreme Events and Disasters to Advance Climate Change Adaptation. A Special Report of Working Groups I and II of the Intergovernmental Pan-el on Climate Change. Cambridge: Cambridge University Press, pp. 3-21.

Karanasios S 2011. New and Emergent ICTS and Climate Change in Developing Countries. Centre for Development Informatics Institute for Development Policy and Management, SED. Manchester: University of Manchester.

Leary N, Adejuwon J, Barros V, Batimaa P et al. 2007. A Stitch in Time: Lessons for Climate Change Adaptation from the AIACC Project. AIACC Working Paper 48. Washington DC: The AIACC Project Office, International START Secretariat.

Lemos MC, Dilling L 2007. Equity in forecasting climate: Canscience save the world's poor? Science and Public Policy, 34(2): 109-116.

Letson D, Llovet I, Podestá G, Royce F, Brescia V et al. 2001. User perspectives of climate forecasts: Crop producers in Pergamino, Argentina. Climate Research, 19: 57-67

Mase AS, Prokopy LS 2014. Unrealized potential: A review of perceptions and use of weather and climate information in agricultural decision making. Weather, Climate, and Society, 6: 47-61. 
Ministry of Environment and Natural Resources Management 2013. Zimbabwe Second National Communication to the United Nations Framework Convention on Climate Change. Harare: Government of Zimbabwe.

Mudombi S, Muchie M 2010. ICTs in Development and Disaster Response: Opportunities and

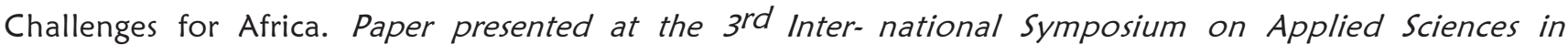
Biomedical and Communication Technologies (ISA-BEL 2010) in Rome, Italy, 7-10 November 2010.

Murphy SJ, Washington R, Downing TE, Martin RV, Ziervogel G et al. 2001. Seasonal forecasting for climate hazards: Prospects and responses. Natural Hazards, 23: 171-196.

Mutekwa VT 2009. Climate change impacts and adaptation in the agricultural sector: The case of smallholder farmers in Zimbabwe. Journal of Sustain- able Development in Africa, 11(2): 237-256.

Mwando M 2012. Zimbabwe III-prepared for Rainfall Extremes, Farmers Say. AlertNet. From <http:// www.trust.org/alertnet/news/zimbabwe-ill-prepared-for-rainfall-extremes-farmers-say> (Retrieved on 21 January 2013).

Nhamo G 2009. Climate change: Double-edged sword for African trade and development, International Journal of African Renaissance Studies - Multi-Inter- and Transdisciplinary, 4(2): 117-139.

Patt A, Gwata C 2002. Effective seasonal climate forecast applications: Examining constraints for subsistence farmers in Zimbabwe. Global Environmental Change, 12: 185-195.

Pfaff A, Broad K, Glantz M 1999. Who benefits from climate forecasts? Nature, 397: 645-650.

Stone RC, Meinke H 2006. Weather, climate, and farmers: An overview. Meteorol Appl, (Supplement):720.

Tall A, Hansen J, Jay A, Campbell B, Kinyangi J, Aggarwal PK, Zougmore R 2014. Scaling up climate services for farmers: Mission Possible. Learning from good practice in Africa and South Asia. CCAFS Report No. 13, Copenhagen: CGIAR Research Program on Climate Change, Agriculture and Food Security (CCAFS).

The Herald 2012. Train Agritex Officers in Weather Data Interpretation. The Herald Online. From <http://www.herald.co.zw/train-agritex-officers-inweather-data-interpretation/> (Retrieved on 12 October 2012).

Thornton PK, Jones PG, Ericksen PJ, Challinor AJ 2011. Agriculture and food systems in sub-Saharan Africa in a $4 æ \% C+$ world. Philosophical Transactions of the Royal Society A, 369: 117-136.

UN/GARDRR 2009. Summary and Recommendations: 2009 Global Assessment Report on Disaster Risk Reduction. Risk and Poverty in a Changing Climate, Invest Today for a Safer Tomorrow. Geneva: United Nations.

UN/ISDR 2010. Terminology: Basic Terms of Disaster Risk Reduction. United Nations/ International Strategy for Disaster Reduction. From <http://www.unisdr.org/eng/library/lib-terminologyeng\%20home.htm> (Retrieved on 20 October 2010).

UNEP 2003. How Will Global Warming Affect My World? A Simplified Guide to the IPCC's "Climate Change 2001: Impacts, Adaptation and Vulnerability".Geneva: United Nations Environment Programme.

UNFCCC 2007. Climate Change: Impacts, Vulnerabilities and Adaptation in Developing Countries. Bonn: United Nations Framework Convention on Climate Change.

Unganai L 2009. Adaptation to climate change amongagropastoral systems: Case for Zimbabwe. IOP Conference Series: Earth and Environmental Science, 6: 1-1. 
Vermeulen SJ, Aggarwal PK, Ainslie A, Angelone C,Campbell BM et al. 2010. Agriculture, Food Security and Climate Change: Outlook for Knowledge, Tools and Action. CCAFS Report 3. Copenhagen:

CGIAR-ESSP Program on Climate Change, Agriculture and Food Security.

Vogel C 2005. "Seven fat years and seven lean years"? Climate change and agriculture in Africa. IDS Bulletin, 36(2): 30-35.

Winsemius HC, Dutra E, Engelbrecht FA, Archer Van Garderen E, Wetterhall F, Pappenberger F, Werner MGF 2014. The potential value of seasonal fore- casts in a changing climate in southern Africa. Hydrology and Earth System Science, 18: 1525-1538.

World Bank 2012. Mainstreaming Adaptation to Climate Change in Agriculture and Natural Resources Management Projects Guidance Notes (6): Identifying Appropriate Adaptation Measures to Climate Change. Washington DC: The World Bank.

World Bank and UN/ISDR 2007. Report on the Status of Disaster Risk Reduction in the Sub-Saharan Africa (SSA) Region. The World Bank and United Nations International Strategy for Disaster Reduction. From <http://www.unisdr.org/eng/partner-netw/wb-isdr/wb- isdr> (Retrieved on 19 August 2013).

Ziervogel G, Bithell M, Washington R, Downing T 2004. Agent-based social simulation: A method for assessing the impact of seasonal climate forecast applications among smallholder farmers. Agricultural Systems, 83(2005): 1-26. 